\title{
Correction to: Numerical simulation of the effect of chimney configuration on the performance of a solar chimney power plant
}

\author{
Mazdak Arzpeyma ${ }^{1}$ (I) Saad Mekhilef ${ }^{2,4} \cdot$ Kazi Md. Salim Newaz ${ }^{1} \cdot$ Ben Horan $^{3} \cdot$ Mehdi Seyedmahmoudian $^{4}$. \\ Naveed Akram ${ }^{1,5} \cdot$ Alex Stojcevski $^{4} \cdot$ Fadi Alnaimat $^{6} \cdot$ Bobby Mathew $^{6}$
}

Published online: 16 April 2021

○) Akadémiai Kiadó, Budapest, Hungary 2021

\section{Correction to: Journal of Thermal Analysis and Calorimetry https://doi.org/10.1007/s10973-021-10567-y}

After online publication of the article, the authors would like to make the second and third authors as co-corresponding authors. The corrected author group with corresponding authorship is given in this correction article.

The original article has been corrected.

Publisher's Note Springer Nature remains neutral with regard to jurisdictional claims in published maps and institutional affiliations.

The original article can be found online at https://doi.org/10.1007/ s10973-021-10567-y.

Mazdak Arzpeyma

mazdak.arzpeyma@gmail.com

Saad Mekhilef

saad@um.edu.my

$\bowtie$ Kazi Md. Salim Newaz

salimnewaz@um.edu.my

1 Department of Mechanical Engineering, Faculty of Engineering, University of Malaya, 50603 Kuala Lumpur, Malaysia

2 Power Electronics and Renewable Energy Research Laboratory (PEARL), Department of Electrical Engineering, Faculty of Engineering, University of Malaya, 50603 Kuala Lumpur, Malaysia
3 School of Engineering, Deakin University, Geelong, VIC 3216, Australia

4 School of Software and Electrical Engineering, Faculty of Science, Engineering and Technology, Swinburne University of Technology, Melbourne, VIC 3122, Australia

5 Department of Mechanical Engineering, Mirpur University of Science and Technology (MUST), Mirpur, AJK 10250, Pakistan

6 Department of Mechanical Engineering, The United Arab Emirate University, P.O. Box 15551, Al Ain, United Arab Emirates 